\title{
Toward a climate downscaling for the Eastern Mediterranean at high-resolution
}

\author{
A. N. Hahmann ${ }^{1}$, D. Rostkier-Edelstein ${ }^{2}$, T. T. Warner ${ }^{1}$, Y. Liu ${ }^{1}$, F. Vandenberghe ${ }^{1}$, and S. P. Swerdlin ${ }^{1}$ \\ ${ }^{1}$ National Center for Atmospheric Research, Boulder, Colorado, USA \\ ${ }^{2}$ Israel Institute for Biological Research, Ness-Ziona, Israel
}

Received: 11 March 2007 - Revised: 10 October 2007 - Accepted: 2 December 2007 - Published: 24 January 2008

\begin{abstract}
As a first step toward downscaling global model simulations of future climates for the eastern Mediterranean Sea and surrounding land area, mesoscale-model simulations with the Pennsylvania State University - National Center for Atmospheric Research (NCAR) mesoscale model, version 5 (MM5) are verified in the context of precipitation amount. The simulations are driven with January NCAR-NCEP reanalysis project (NNRP) lateral-boundary conditions and assimilate surface and upper air observations. The results of the simulations compare reasonably well with rain gauge and satellite estimates of monthly total precipitation, and the model reproduces the overall trends in inter-annual precipitation variability for one test region. Cyclones during the period were tracked, and their properties identified.
\end{abstract}

\section{Introduction}

The complete state of the atmosphere cannot be observed. Only samples in the form of mostly point observations are available at irregular intervals in both time and space. To obtain geographically more detailed information either dynamical or statistical methods are used to downscale coarseresolution re-analysis or GCM output to the high-resolution needed over the area of interest. In the dynamical downscaling method, a limited area atmospheric model is integrated over the area and period of interest using large-scale re-analysis fields as initial and lateral conditions. The output of these integrations is used to fill both small and large space and time gaps. The result of the dynamical downscaling method is then a collection of mesoscale model simulations, or mesoscale re-analysis, which are consistent with the high-resolution details of the region of interest such as the coastline and the local orography.

Correspondence to: A. N. Hahmann

(hahmann@ucar.edu)
We use the PSU/NCAR mesoscale model, version 5 (MM5, Grell et al., 1995), and the community Weather Research and Forecast model (ARW-WRF, Skamarock et al., 2005) to dynamically downscale the climate of the eastern Mediterranean and the adjacent countries of the Middle East. The focus of the study is on precipitation and other components of the water cycle: fields that determine the balance between water supply and demand that could change significantly for future climate scenarios.

A number of regional climate downscaling studies over Europe and the eastern Mediterranean have been reported during the past few years. Some of them are relevant to the current work and will be reviewed here; a complete literature review is beyond the scope of this manuscript. Giorgi et al. (2004a,b) analyzed present and future climate over Europe as simulated by the regional climate model (RCM) RegCM nested within the global atmospheric model HadAMH. In their study, the RegCM, which has a dynamical core equivalent to that of the hydrostatic version of MM5, was used at a $50 \mathrm{~km}$ grid interval. Similar nesting strategies, using modified versions of RegCM and HadAMH, at similar grid intervals, have been implemented over the eastern Mediterranean and adjacent land areas by Krichak et al. (2005), and Krichak et al. (2007). The use of a hydrostatic RCM represents a limitation, because high spatial resolution is not possible. However, high spatial resolution is critical to success in capturing essential features of the eastern Mediterranean climate. Kunstmann et al. (2007) studied regional climate change in the Middle East with special focus on the Upper Jordan River area. Their work is based on dynamic downscaling climate scenarios of ECHAM4 with MM5 in two nesting steps of 54 and $18 \mathrm{~km}$ grid spacing. While RCMs are limited by horizontal resolution constraints, limited area numerical weather prediction (NWP) models, i.e. MM5, present a main restriction when used in climate studies because they drift from the large-scale solution of the driving global model over time. Neither reference to

Published by Copernicus Publications on behalf of the European Geosciences Union. 


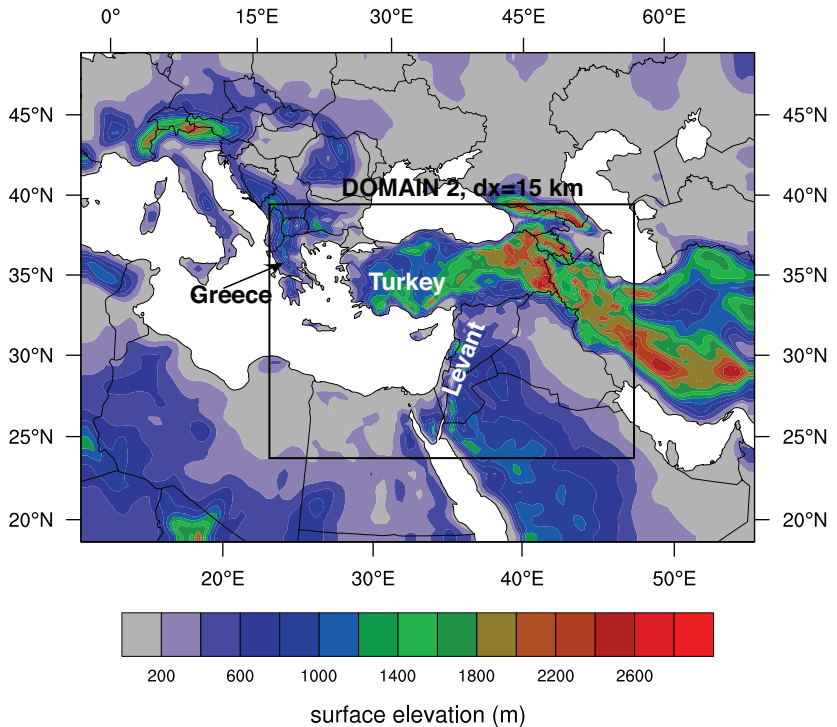

Fig. 1. Computational areas of the coarse $(45 \mathrm{~km}$ grid interval $)$ and nested $(15 \mathrm{~km})$ model grids. Also shown is the terrain elevation (meters) in the coarse domain.

this restriction nor to methods for overcoming it is made by Kunstmann et al. (2007). As described in the following sections, our work is devoted to simulating the regional climate at a high spatial resolution, using a limited area NWP model, with an emphasis on keeping the correct large-scale pattern over time.

The first step in our study is the use of the MM5 model to replicate the present-day hydro-climate of the area. To accomplish this, the model has been run for six Januaries (2001-2006) using NCAR-NCEP (National Centers for Environmental Prediction) Reanalysis Project (NNRP) archived global analyses for initial and lateral-boundary conditions. Surface and upper-air observations are assimilated on the model grids to provide "the best" possible model climatology of the region and to keep the large-scale component of the model solution as correct as possible.

\section{Meteorological problem}

The climatological transition area of the eastern Mediterranean is very interesting and complex meteorologically. Superimposed on the large-scale processes are mesoscale effects related to the complex coastline and nearby mountains (Fig. 1). There are strong near-coastal gradients in observed precipitation (Fig. 2b, c), the positions of which have huge hydrologic consequences. If these gradients shift position in new climate regimes, the implications for water supply are great. The cold-season precipitation in this area is associated with Mediterranean cyclones, for which there are many climatological descriptions (e.g., HMSO, 1962; Alpert et al., 1990; Trigo et al., 1999; Genovés et al., 2006; Alpert et

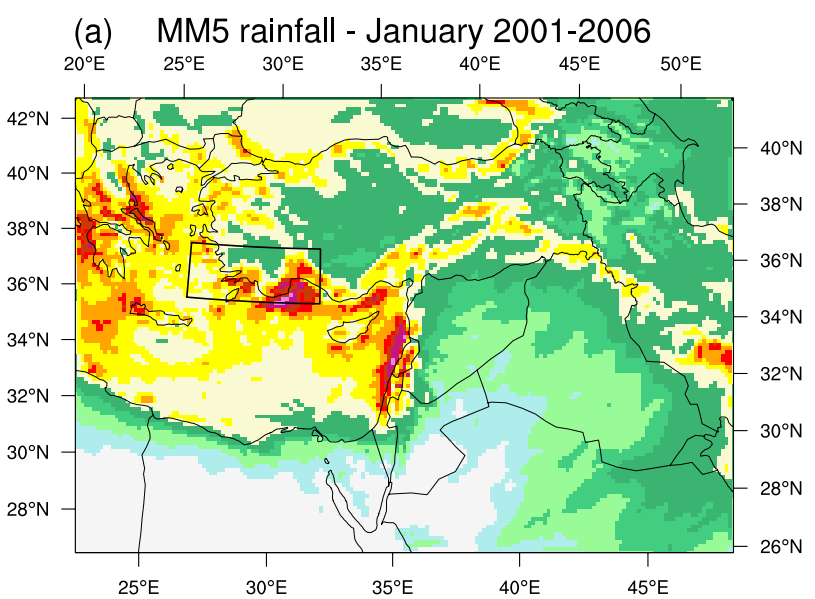

(b) Gauge rainfall - January 2001-2006

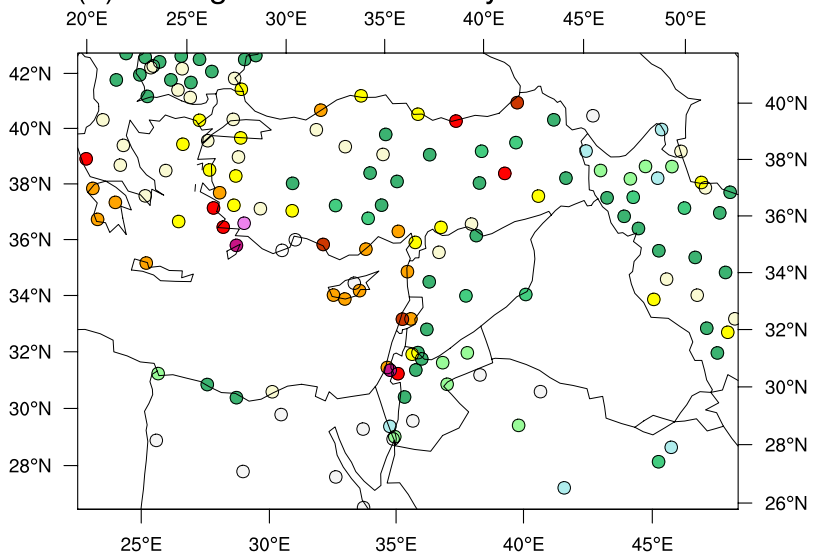

(c) TRMM Rainfall - January 2001-2006

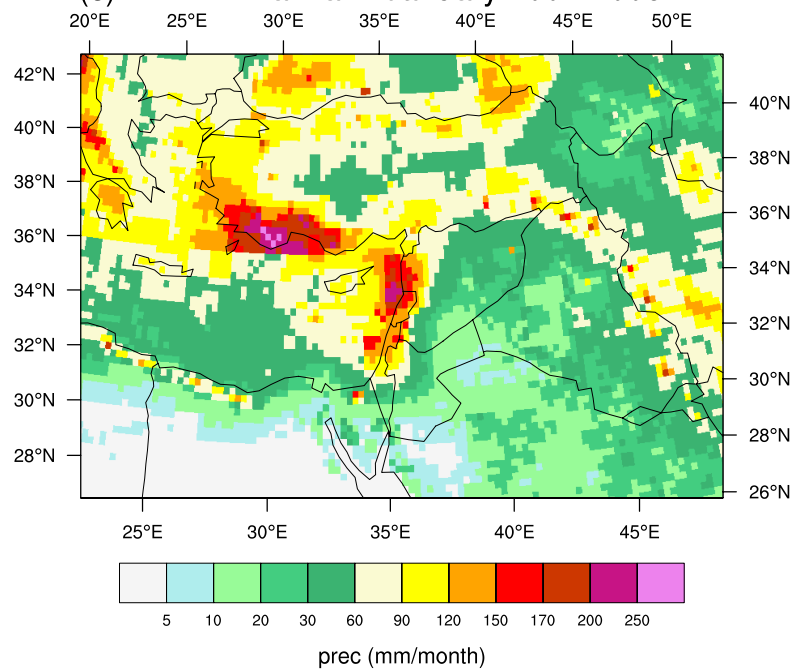

Fig. 2. January precipitation for 2001-2006 over the domain-2 area (Fig. 1) based on (a) MM5 simulations, (b) rain gauge data, and (c) data from the merged Tropical Rainfall Measurement Mission (TRMM) product. Information about the merged TRMM precipitation data can be found at http://disc.sci.gsfc.nasa.gov/data/datapool/ TRMM/01_Data_Products/02_Gridded/index.html. 
al., 2006). Thus, simulating the correct distribution of precipitation is largely dependent upon simulating the correct cyclone tracks, intensity, and interaction with the local topography. In this paper, we will assess the success of the model by comparing the model-simulated precipitation with gauge measurements and satellite-derived estimates of rainfall in terms of the average monthly totals, and their interannual variability.

\section{Modeling approach}

We employed MM5 to downscale the cold-season precipitation, using NNRP lateral boundary conditions, and assimilating surface and radiosonde measurements on the grid interior. This will establish the ability of the model to replicate the observed hydro-climate under optimal conditions. The model being used in the initial part of this study is MM5 (version 3.6) because to date it has been much more thoroughly tested than has WRF. The model is run in a continuous assimilation mode, where observations are assimilated using Newtonian relaxation, as described by Liu et al. (2006; 2008); we refer to this method as four-dimensional data assimilation (FDDA). When the ability of MM5 to successfully reproduce the major aspects of the current hydro-climate of the area has been confirmed, the transition to WRF will take place. The model configuration is summarized as follows: non-hydrostatic dynamics; one-way interactive nesting; time-dependent lateral-boundary conditions relaxed toward NNRP analyses; Grell (1993) cumulus parameterization on both grids; modified Medium Range Forecast (MRF) model planetary boundary-layer parameterization (Hong and Pan, 1996; Liu et al., 2006); Noah land-surface model (Chen and Dudhia, 2001); SSTs interpolated from the NCEP Version 2.0 global SST data set (Reynolds et al., 2002), which is updated weekly on a $1^{\circ} \times 1^{\circ}$ grid; 36 computational levels, with approximately 12 levels within the lowest $1 \mathrm{~km}$; and a horizontal grid increment of $45 \mathrm{~km}$ on the outer grid and $15 \mathrm{~km}$ on the inner grid. Figure 1 shows the computational area of the two grids, along with the terrain elevation on the outer grid.

This paper focuses on a single month, January. After the model-downscaled climatography for that month is studied and verified, climatographies for the other winter months will be generated with the same modeling system. The NNRP data set, used for lateral-boundary conditions, and the available observations allow us to define a 30-year climatography. The MM5 model using FDDA was re-initialized every five days, using the NNRP analysis for initial conditions. Each simulation overlaps the previous one by $12 \mathrm{~h}$, in order to avoid using the first $12 \mathrm{~h}$, during which the model is spinning up mesoscale processes. Frequent mesoscale model initializations ensure the correct large-scale solution throughout the simulated month.
The verification of the simulations is in the context of precipitation fields and cyclone-pressure statistics. The modeled precipitation fields are being evaluated in terms of monthly totals and their inter-annual variability. A gridded estimate of monthly precipitation over the Mediterranean is obtained from a $0.25^{\circ} \times 0.25^{\circ}$ rainfall product that uses calibrated satellite IR measurements, Tropical Rainfall Measuring Mission (TRMM) data, and gauge totals, as described by Huffman et al. $(2007)^{1}$. We have chosen to validate the modelsimulated rainfall because it is completely independent of the assimilated observations. Furthermore, because many aspects of model physics typically need to operate properly for precipitation to be correctly simulated, this will be a good test of the downscaling system's ability to define unobserved or poorly observed fields. The sea-level pressure field (sampled every $6 \mathrm{~h}$ from both MM5 and NNRP) is used to define storm tracks and central pressures. The cyclones are identified and tracked using methods described by Benestad and Chen (2006) and Trigo et al. (1999). These are later summarized over $2.5^{\circ} \times 2.5^{\circ}$ latitude/longitude boxes and over a monthly period.

\section{Results}

Results are presented here for six Januaries, from 2001 to 2006. Figure 2a shows the average January precipitation based on MM5 simulations, for the inner computational domain (15 km horizontal grid spacing). Significant precipitation maxima over land are along the coastlines of the Levant, Turkey, and Greece. There is also significant precipitation over the Mediterranean to the south of Greece. The precipitation gradient is very large along the North African coastline. The gradient is somewhat less along the Levant and Turkey coasts, but it is still large. The rain gauge data in Fig. $2 b$ are consistent with the MM5 estimates, showing the greatest amounts along the coasts of the Levant, Turkey and Greece with large coastal gradients. The coastal amounts from the satellite/gauge merged data show a similar pattern (Fig. 3c), but there is less precipitation estimated over the central and southern Mediterranean.

Lastly, the inter-annual variation in monthly precipitation averaged over the land area within the box in Fig. 2a (southwest of Turkey) is shown in Fig. 3a. This area was selected somewhat arbitrarily near a maximum in MM5-simulated precipitation to illustrate a typical regional year-to-year variability. The MM5 simulation consistently underestimates the land precipitation amounts as compared to the gauge-, GPCC-, and merged TRMM-derived area averages. However, this underestimation might simply be an artifact of the selected averaging region; in areas of large rainfall gradients,

\footnotetext{
${ }^{1}$ The geographical coverage of this merged rainfall product is $50^{\circ} \mathrm{S}-50^{\circ} \mathrm{N}, 180^{\circ} \mathrm{W}-180^{\circ} \mathrm{E}$. For further information see http://disc.sci.gsfc.nasa.gov/data/datapool/TRMM/ 01_Data_Products/02_Gridded/index.html
} 
(a) area-averaged rainfall

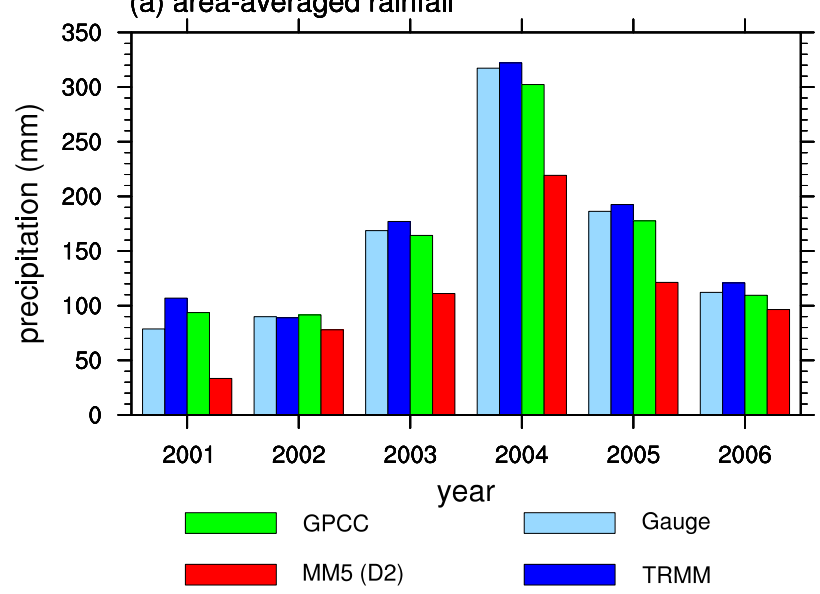

(b) area-total cyclone count

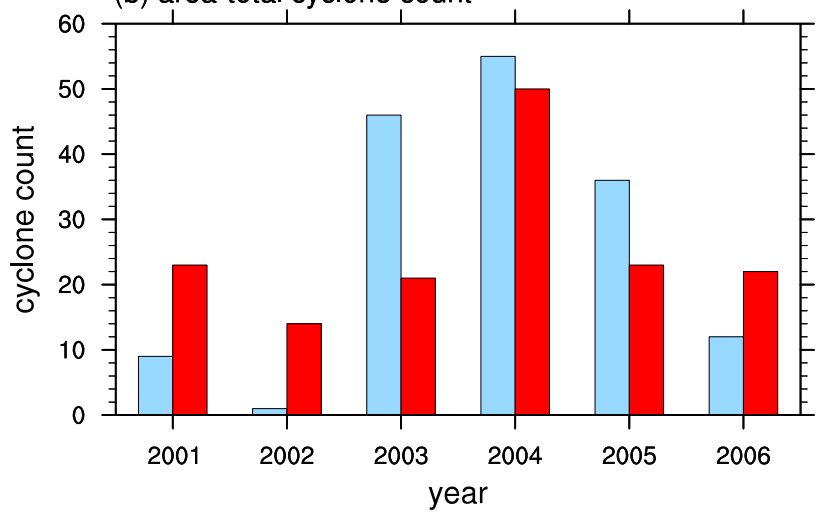

NNRP
MM5 (D1)
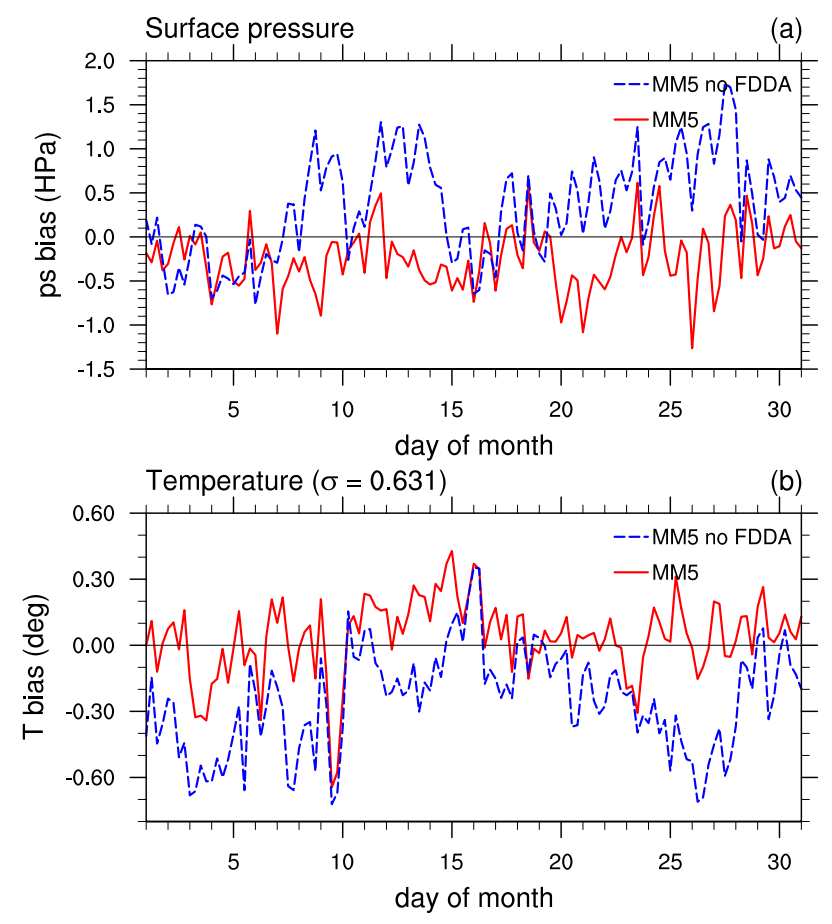

Fig. 4. Domain-averaged MM5-NNRP bias on the coarse domain, for January 2002 for: (a) surface pressure (hPa) and (b) air temperature $\left({ }^{\circ} \mathrm{C}\right.$ ) at model level $\sim 670 \mathrm{hPa}$. Simulations are with (solid line) and without (dash line) assimilation of observations.

ior to that of the observed inter-annual variations in rainfall for both the model and the observations.

\section{Summary and discussion}

The results described here illustrate a preliminary assessment of the ability of the MM5 model, using continuous assimilation of observations, to downscale precipitation for the eastern Mediterranean and surrounding land areas. This work is the initial phase of a larger project that is aimed at building a system that is able to downscale changes in the water cycle that result from the climate change predicted by a low-resolution atmospheric general circulation model. Results from the system will be especially relevant for other water-limited regions of the world.

In these initial simulations, no tuning of the model physics or the nudging coefficients was performed to optimize model performance for the region. The four dimensional assimilation of data of course permits the model to show more skill than it would have if run without data assimilation, but there are clearly many data voids in our computational area because of the existence of water bodies and sparsely populated areas. The added value of the assimilation of observations is assessed by comparing MM5 runs with and without FDDA. Figure 4a shows the outer domain averaged bias in 
the simulated surface pressure relative to the NNRP analysis, for January 2002. The solid line shows results when data assimilation is implemented and the dashed line when it is not. Figure $4 \mathrm{~b}$ shows a similar comparison for air temperature at $\sim 670 \mathrm{hPa}$. These results show the considerable contribution of the assimilation of observations in keeping the mesoscale solution in the correct synoptic envelope. Future climate simulations will lack the assimilation of observations, and alternative strategies will have to be applied to keep the mesoscale model from drifting. For instance, spectral nudging techniques, by which large-scale flow conditions from the global model force the mesoscale model within the integration area, have been implemented in the context of dynamical downscaling (see e.g., von Storch et al., 2000; Kanamaru and Kanamitsu, 2007).

Visual comparison of the amount and geographic distribution of monthly rainfall between the model and the observations reveals considerable skill in the model simulation. This is not only true for the 2001-2006 mean, but is also true for individual years (not shown). Because the skill with which MM5 simulates precipitation is dependent on its skill at replicating the properties of the cyclones, further verification will involve comparing the simulated and observed pressures when cyclones make landfall on the Mediterranean coast, where surface pressure measurements are available.

The initial simulations reported in this paper will be repeated later without the use of observations but using grid nudging towards the driving analysis similar to that done by Von Storch et al. (2000). The comparison of the simulated and observed precipitation in these two runs establishes the veracity of this modeling system for simulation of the regional water cycle. This process of model verification and adaptation for the area will then be repeated with WRF for the entire winter season, when most of the precipitation occurs. After this step, the model that better represents the regional and local climate will be selected and run for the same period using lateral-boundary conditions from a simulation of the present global climate by the NCAR Community Atmospheric Model (CAM) driven by observed sea-surface temperatures and land use. Lastly, the regional model will be run with the lateral-boundary conditions provided by future climate simulations conducted for the Fourth IPCC assessment report with the coupled ocean-land-atmosphere Community Climate System Model, CCSM. This regional-model output will be compared with the regional-model simulation of the present climate in order to assess the impact of future climate forcing scenarios on the components of the water cycle in this geographic area.

Acknowledgements. Rasmus E. Benestad at the Norwegian Meteorological Institute and the Norwegian Research Council's RegClim programme is acknowledged for providing the software for cyclone tracking, and guidance on how to use it. A. Negri of NASA provided assistance relative to the use of TRMM data. We would like to also thank J. Knievel for his careful editing of the manuscript.
Edited by: P. Alpert, H. Saaroni, and E. Heifetz

Reviewed by: two anonymous referees

\section{References}

Alpert, P., Krichak, S. O., Dayan, M., and Shafir, H.: Climatic trends over the Eastern Mediterranean: past and future projections, CLIVAR Exchanges, 11(2), 12-13, 2006.

Alpert, P., Neeman, B. U., and Shay-El, Y.: Climatological analysis of Mediterranean cyclones using ECMWF data, Tellus, 42A, 6577, 1990.

Benestad, R. E. and Chen, D.: The use of a calculus-based cyclone identification method for generating storm statistics, Tellus, A58, 473-486, doi: 10.1111/j.1600-0870.2006.00191.x, 2006.

Chen, F. and Dudhia, J.: Coupling an advanced landsurface/hydrology model with the Penn State/NCAR MM5 modeling system. Part I: Model implementation and sensitivity, Mon. Wea. Rev. 129, 569-585, 2001.

Genovés, A., Campins, J., and Jansà, A.: Intense storms in the Mediterranean: A first description from the ERA-40 perspective, Adv. Geosci., 7, 163-168, 2006, http://www.adv-geosci.net/7/163/2006/.

Giorgi, F., Bi, X., and Pal, J.: Mean, interannual variability and trends in a regional climate change experiment over Europe. I. Present-day climate (1961.1990), Clim. Dynam., 22, 733-756, 2004a.

Giorgi, F., Bi, X., and Pal, J.: Mean, interannual variability and trends in a regional climate change experiment over Europe. II. Climate change scenarios (2071.2100), Clim. Dynam., 23, 839858, 2004b.

Grell, G.: Prognostic evaluation of assumptions used by cumulus parameterizations, Mon. Wea. Rev., 121, 764-787, 1993.

Grell, G. A., Dudhia, J., and Stauffer, D. R.: A description of the Fifth-generation Penn State/NCAR Mesoscale Model (MM5), NCAR/TN-398, NCAR, Boulder, CO, 122 pp., 1995.

HMSO: Weather in the Mediterranean I: General Meteorology, 2nd Ed., Her Majesty's Stationery Office, 362 pp., 1962.

Hong, S.-Y. and Pan, H.-L.: Nonlocal boundary layer vertical diffusion in a medium-range forecast model, Mon. Wea. Rev., 124, 2322-2339, 1996.

Huffman, G. J., Adler, R. F., Bolvin, D. T., Gu, G., Nelkin, E. J., Bowman, K. P., Hong, Y., Stocker, E. F., and Wolff, D. B.: The TRMM multi-satellite precipitation analysis: Quasi-global, multi-year, combined-sensor precipitation estimates at fine scale, J. Hydrometeorol., 8, 38-55, 2007.

Kanamaru, H. and Kanamitsu, M.: Scale-selective bias-correction in a downscaling of global analysis using a regional model, Mon. Wea. Rev., 135, 334-350, 2007.

Krichak, S. O., Alpert, P., Bassat, K., and Kunin, P.: The surface climatology of the eastern Mediterranean region obtained in a three-member ensemble climate change simulation experiment, Adv. Geosci., 12, 67-80, 2006, http://www.adv-geosci.net/12/67/2006/.

Kunstmann, H., Suppan, P., Heckl, A., and Rimmer, A.: Regional climate change in the Middle East and impact on hydrology in the Upper Jordan catchment, Quantification and Reduction of Predictive Uncertainty for Sustainable Water Resources Management (Proceedings of Symposium HS2004 at IUGG2007, Perugia, July 2007), IAHS Publ. 313, 2007. 
Liu, Y., Chen, F., Warner, T., and Basara, J.: Verification of a mesoscale data-assimilation and forecasting system for the Oklahoma City area during the Joint Urban 2003 Field Project, J. Appl. Meteorol. Clim., 45, 912-929, 2006.

Liu, Y., Warner, T. T., Bowers, J. F., Carson, L. P., Chen, F., Clough, C. A., Davis, C. A., Egeland, C. H., Halvorson, S. F., Huck Jr., T. W., Malone, R. E., Rife, D. L., Sheu, R.-S., Swerdlin, S. P., and Weingarten, D. S.: The operational mesogamma-scale analysis and forecast system of the U.S. Army Test and Evaluation Command. Part 1: Overview of the modeling system, the forecast products, and how the products are used, J. Appl. Meteorol. Clim., in press, 2008.
Skamarock, W. C., Klemp, J. B., Dudhia, J., Gill, O., Barker, D. M., Wang, W., and Powers, J. G.: A description of the Advanced Research WRF Version 2, NCAR/TN-468+STR, 100 pp., 2005.

Reynolds, R. W., Rayner, N. A., Smith, T. M., Stokes, D. C., and Wang, W.: An improved in situ and satellite SST analysis for climate, J. Climate, 11, 3320-3323, 2002.

Trigo, I. F, Davies, T. D., and Bigg, G. R.: Objective climatology of cyclones in the Mediterranean region, J. Climate, 12, 1685-1696, 1999.

Von Storch, H., Langenberg, H., and Feser, F.: A spectral nudging technique for dynamical downscaling purposes, Mon. Wea. Rev., 128, 3664-3673, 2000. 